\title{
C-reactive Protein Overexpression in the Background Liver of Hepatitis B Virus-Associated Hepatocellular Carcinoma Is a Prognostic Biomarker
}

\author{
Jin Ho Shin · Eunsil Yu \\ Eun Na Kim • Chong Jai Kim \\ Department of Pathology, Asan Medical Center, \\ University of Ulsan College of Medicine, Seoul, \\ Korea
}

\author{
Received: January 23, 2018 \\ Revised: June 26, 2018 \\ Accepted: July 14, 2018 \\ Corresponding Author \\ Chong Jai Kim, MD, PhD \\ Department of Pathology, Asan Medical Center, \\ University of Ulsan College of Medicine, \\ 88 Olympic-ro 43-gil, Songpa-gu, Seoul 05505, \\ Korea \\ Tel: +82-2-3010-4516 \\ Fax: $+82-2-472-7898$ \\ E-mail: ckim@amc.seoul.kr
}

\begin{abstract}
Background: Chronic hepatitis B virus (HBV) infection is a leading cause of hepatocellular carcinoma (HCC). Peripheral blood C-reactive protein (CRP) concentration and CRP overexpression in $\mathrm{HCC}$ cells are proven to be prognostic markers for HCC, but the significance of CRP expression in non-neoplastic hepatocytes, which are the primary origin of CRP, has not been studied. This study was conducted to determine the clinicopathologic significance of CRP immunoreactivity in the background liver of HBV-associated HCC. Methods: CRP immunostaining was done on tissue microarrays of non-neoplastic liver tissues obtained from surgically resected, treatment-naïve HBV-associated HCCs $(n=156)$. The relationship between CRP immunoreactivity and other clinicopathologic parameters including cancer-specific survival was analyzed. CRP immunoreactivity was determined using a 4-tier grading system: grades $0,1,2$, and 3. Results: CRP was positive in 139 of 156 cases (89.1\%) of non-neoplastic liver in patients with HCCs: grade 1 in 83 cases (53.2\%); grade 2 in 50 cases (32.1\%); and grade 3 in six cases (3.8\%). The patients with diffuse CRP immunoreactivity (grade 3 ) had decreased cancer-specific survival $(p=.031)$ and a tendency for shorter interval before early recurrence $(p=.050)$. The degree of CRP immunoreactivity correlated with serum CRP concentration $(p<.001)$. Conclusions: CRP immunoreactivity in non-neoplastic liver is a novel biomarker for poor cancer-specific survival of HBV-associated HCC and correlates with serum CRP concentration.
\end{abstract}

Key Words: Carcinoma, hepatocellular; C-reactive protein; Hepatitis B virus; Immunohistochemistry; Prognosis
Acute-phase reactant C-reactive protein (CRP) is primarily synthesized by hepatocytes in association with inflammation. ${ }^{1}$ Pro-inflammatory cytokines interleukin (IL)-6 and IL-1 upregulate CRP transcription, ${ }^{2,3}$ and chronic inflammatory conditions of infectious (e.g., bacteria, virus) and noninfectious origins (e.g., toxins, obesity) provide the microenvironment for carcinogenesis primarily by inducing instability of the cellular genome. ${ }^{4,5}$ Inflammatory cellular infiltrates induce the pooling of pro-inflammatory cytokines and oxidative stress at the site of inflammation. Common molecules involved in inflammation-induced carcinogenesis include prostaglandins, nuclear factor $\kappa \mathrm{B}$, and cytokines. The prognostic significance of CRP blood level has been shown in several human malignancies such as hepatocellular carcinoma (HCC) ${ }^{6,7}$ CRP-based risk assessment algorithms, combined with other parameters such as absolute neutrophil count and blood albumin level, also serve as prognostic indices. ${ }^{8-10}$

$\mathrm{HCC}$ is a viral infection-associated cancer posing a significant health-care burden worldwide. ${ }^{11}$ We have shown that CRP immunoreactivity in HCC cells is a prognostic marker of treat- ment-naive HCC. ${ }^{12}$ However, the clinicopathologic significance of CRP expression in non-neoplastic background liver, which should be the primary origin of CRP, has not been studied. We postulated that CRP expression in non-neoplastic liver would have pathobiological meaning because the liver is primarily responsible for CRP synthesis. Chronic infection by hepatitis B virus (HBV) is a leading cause of HCC, and this study was conducted to determine the clinicopathologic significance of CRP immunoreactivity in non-neoplastic liver tissue in $\mathrm{HBV}$-associated HCC cases.

\section{MATERIALS AND METHODS}

Patients and tissue samples

A total of 156 cases of surgically resectable (R0) HBV-associated HCCs was retrieved from the files of the Department of Pathology, Asan Medical Center, Seoul, Republic of Korea. A tumor recurrence within 2 years after surgical resection was defined as early recurrence. The patients have provided written informed con- 
sent, and this study was approved by the Institutional Review Board of Asan Medical Center, Seoul, Republic of Korea (S20110931).

\section{Tissue microarray and immunohistochemistry}

Tissue microarrays (TMAs) were generated using paraffin blocks of formalin-fixed liver tissues. The hematoxylin and eosinstained slides were reviewed to select the regions for TMA construction, and 2-mm-thick tissue cores were obtained in duplicates from the donor blocks and transferred onto the recipient blocks. From each TMA, 4- $\mu$ m-thick sections were obtained, and subsequent immunohistochemistry was done. For CRP immunohistochemical staining, a rabbit polyclonal anti-CRP antibody (Abcam, Cambridge, UK) was used at 1:1,000 dilution. The sections were placed on silanized slides, and heat-induced epitope retrieval was performed by treating the slides with Cell Conditioning 1 buffer for 32 minutes in a BenchMark XT automatic immunostainer (Ventana Medical Systems, Tucson, AZ, USA). An OptiView DAB IHC Detection Kit (Ventana Medical Systems) was used for the detection of signal. Evaluation of the immunoreactivity was done by a pathologist (C.J.K.), who was blinded to clinical information, using a 4-tier grading system: negative as grade 0 ; positive in less than $10 \%$ of tumor cells as grade 1 ; positive in less than $50 \%$ of tumor cells as grade 2 ; and diffusely positive in more than $50 \%$ of tumor cells as grade 3 .

\section{Statistical analysis}

For statistical evaluation of the significance of the clinicopathologic parameters, the analyses of noncontinuous categorical variables were done using linear by linear association (chi-square test for trend). We also used logistic regression analysis for multivariate analysis of statistically significant variables in univariate analysis. The relationship between serum CRP level and liver tissue CRP immunoreactivity was analyzed using Spearman correlation analysis and displayed using dot plot. The KaplanMeier method and Cox regression analysis were used in the survival analysis. SPSS ver. 18.0 software (SPSS Inc., Chicago, IL, USA) was used for all statistical analyses.

\section{RESULTS}

\section{CRP immunoreactivity in liver tissues}

CRP expression was observed as cytoplasmic immunoreactivity. Immunoreactive CRP was found in 139 of 156 cases (89.1\%), and 17 cases (10.9\%) were negative. Among CRP-positive cases $(\mathrm{n}=139)$, more than half $(\mathrm{n}=83 ; 59.7 \%)$ showed grade $1 \mathrm{immu-}$ noreactivity, followed by the cases with grade $2(\mathrm{n}=50,36.0 \%)$ and grade $3(n=6,4.3 \%)$ immunoreactivity (Fig. 1). The patient demographics and the relationship between CRP immunoreactivity and other clinicopathologic parameters are summarized in Tables 1 and 2. Among the clinicopathologic parameters analyzed, tumor size and serum CRP concentration significantly varied according to CRP immunoreactivity ( $\mathrm{p}<.001$ and $\mathrm{p}<.005$, respectively). Serum CRP concentration (median, $0.135 \mathrm{mg} / \mathrm{dL}$; range, 0.03 to $6.95 \mathrm{mg} / \mathrm{dL}$ ) showed a positive linear correlation with CRP immunoreactivity $(\mathrm{p}<.001$; rho $=0.513)$ (Fig. 2). The number of tumors ( $\mathrm{p}=.058)$, serum $\alpha$-fetoprotein level $(\mathrm{p}=.056)$, and Edmondson-Steiner histologic grade $(\mathrm{p}=.055)$ also tended to be different depending on the grade of CRP immunoreactivity.

Of note, CRP immunoreactivity grade 3 was exclusively associated with the presence of satellite nodules $(\mathrm{p}<.005)$. Furthermore, the patients with CRP immunoreactivity grade 3 showed significantly shorter cancer-specific survival (median, 89.3 months; range, 5 to 104 months) compared with CRP-negative or nondiffuse immunopositive cases (median, 60.7 months; range, 8 to 100 months; $\mathrm{p}<.05$ ) (Fig. 3A). Early recurrence occurred in 63 cases (40.4\%). Recurrence-free survival tended to be different between strong and diffuse immunopositive cases (grade 3 ) and CRP-negative or nondiffuse immunopositive cases (grades 0,1 , and 2). The CRP grade 3 group tended to have shorter time before recurrence (median, 37.8 months; range, 2 to 100 months) than CRP-negative or nondiffuse immunopositive cases did (median, 67.4 months; range, 2 to 103 months; $\mathrm{p}=.050$ ) (Fig. 3B).

Multiple logistic analysis showed serum CRP level greater than $1 \mathrm{mg} / \mathrm{dL}$ to be independently correlated with high CRP grade $(\mathrm{p}=$ .017 ; odds ratio, $12.229 ; 95 \%$ confidence interval, 1.573 to 95.087), whereas tumor size greater than $5 \mathrm{~cm}$ and satellite nodule presence are not (Table 3). Kaplan-Meier survival curves demonstrated shorter survival period in satellite nodule-present group (median, 34.0 months; range, 17 to 64 months; $\mathrm{p}<.001$ ) (Fig. 3C) and vascular invasion-present group (mean, 77.4 months; range, 67 to 88 months; $\mathrm{p}=.001$ ) (Fig. 3D). Cox regression analysis results suggest that the presence of satellite nodule is an independent factor affecting cancer-specific survival (Table 4). Vascular invasion and high-grade CRP immunoreactivity might have independent influence on survival rate; however, statistical significance was not observed.

\section{DISCUSSION}

The primary findings of this study are as follows: (1) CRP expression is relatively common in the background liver tissues 

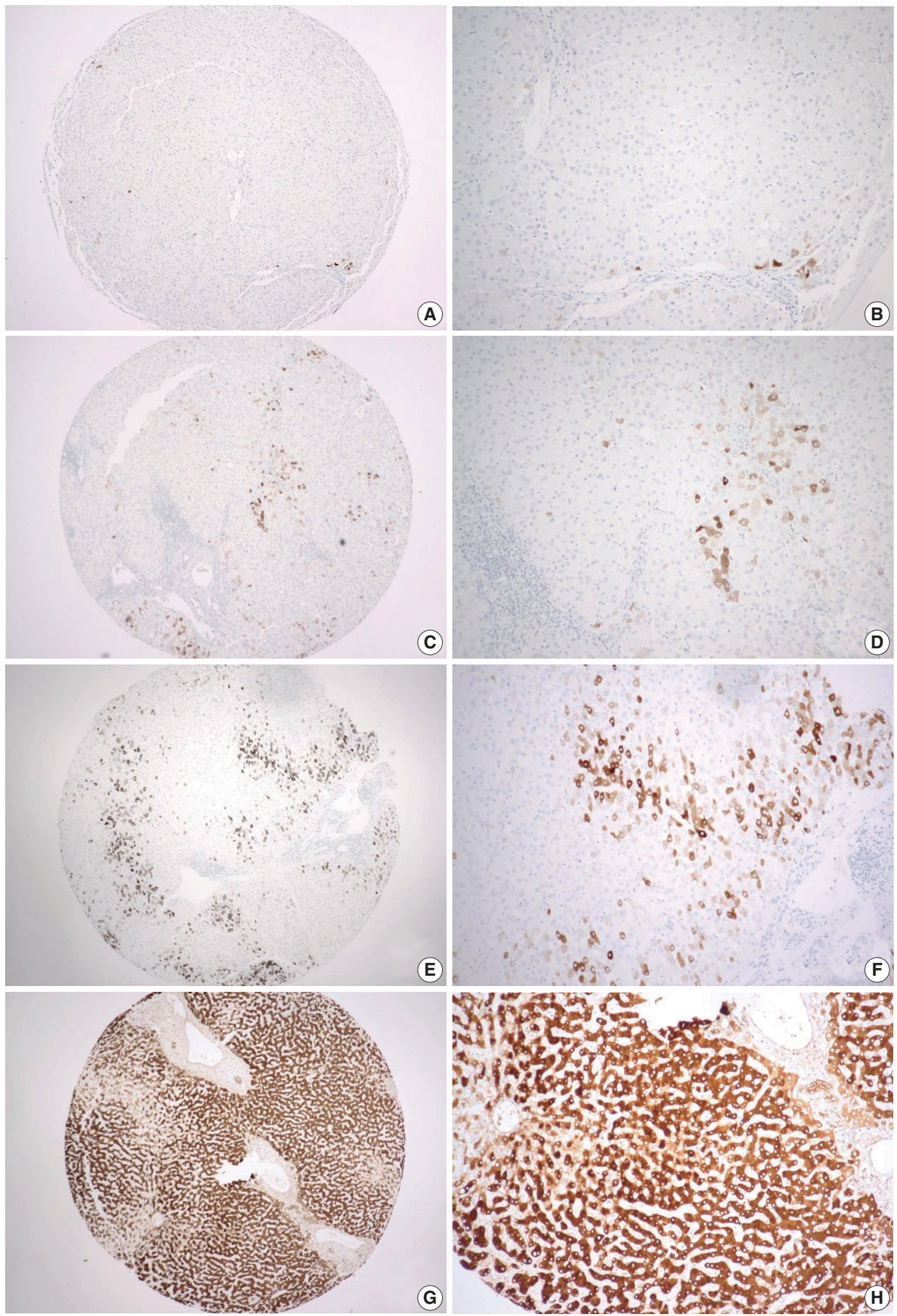

Fig. 1. Cytoplasmic C-reactive protein immunoreactivity in non-neoplastic hepatocytes in treatment-naive, surgically resected HBV-associated hepatocellular carcinoma cases. Immunoreactivity was determined using a 4-tier grading system: A-B, grade 0; C-D, grade 1; E-F, grade 2; and $\mathrm{G}-\mathrm{H}$, grade 3. 
Table 1. Clinical parameters and their relationship with CRP immunoreactivity

\begin{tabular}{|c|c|c|c|c|c|}
\hline Clinical parameter & CRP grade 0 & CRP grade 1 & CRP grade 2 & CRP grade 3 & p-value \\
\hline Sex & & & & & .590 \\
\hline Male & $10(6.4)$ & $63(40.4)$ & $37(23.7)$ & $4(2.6)$ & \\
\hline Female & $7(4.5)$ & $20(12.8)$ & $13(8.3)$ & $2(1.3)$ & \\
\hline Age (yr) & & & & & .764 \\
\hline$<60$ & $14(9.0)$ & $60(38.5)$ & $36(23.1)$ & $5(3.2)$ & \\
\hline$\geq 60$ & $3(1.9)$ & $23(14.7)$ & $14(9.0)$ & $1(0.6)$ & \\
\hline Tumor size $(\mathrm{cm})$ & & & & & .000 \\
\hline$<5$ & $17(10.9)$ & $67(42.9)$ & $31(19.9)$ & $3(1.9)$ & \\
\hline$\geq 5$ & 0 & 16 (10.3) & $19(12.2)$ & $3(1.9)$ & \\
\hline Serum AFP (ng/mL) & & & & & .056 \\
\hline$<400$ & $40(25.6)$ & $29(18.6)$ & $26(16.7)$ & $16(10.3)$ & \\
\hline$\geq 400$ & $24(15.4)$ & $11(7.1)$ & 5 (3.2) & $5(3.2)$ & \\
\hline Serum CRP (mg/dL) & & & & & .002 \\
\hline$<1$ & $12(7.7)$ & $43(27.6)$ & $28(17.9)$ & $2(1.3)$ & \\
\hline$\geq 1$ & 0 & $3(1.9)$ & $5(3.2)$ & $3(1.9)$ & \\
\hline BCLC stage & & & & & .497 \\
\hline A & $17(10.9)$ & $78(50)$ & $46(29.5)$ & $6(3.8)$ & \\
\hline $\mathrm{B}$ & 0 & $5(3.2)$ & $4(2.6)$ & 0 & \\
\hline Fibrosis stage (Batts-Ludwig) & & & & & .773 \\
\hline Stage 1,2 & $3(1.9)$ & $13(8.3)$ & $7(4.5)$ & $1(0.6)$ & \\
\hline Stage 3,4 & $14(9.0)$ & $70(44.9)$ & $43(27.6)$ & $5(3.2)$ & \\
\hline Microvascular invasion & & & & & .890 \\
\hline Not identified & $14(9.0)$ & $57(36.5)$ & $33(21.1)$ & $4(2.6)$ & \\
\hline Present & $3(1.9)$ & $26(16.7)$ & $17(10.9)$ & $2(1.3)$ & \\
\hline Tumor number & & & & & .058 \\
\hline Less than 3 & $17(10.9)$ & $80(51.3)$ & $43(27.6)$ & $6(3.8)$ & \\
\hline 3 or more & 0 & $3(1.9)$ & $7(4.5)$ & 0 & \\
\hline Satellite nodule & & & & & .099 \\
\hline Absent & $17(10.9)$ & $78(50)$ & $48(30.8)$ & $4(2.6)$ & \\
\hline Present & 0 & $5(3.2)$ & $2(1.3)$ & $2(1.3)$ & \\
\hline Edmondson-Steiner grade (worst) & & & & & .169 \\
\hline Grade 1, 2 & $7(4.5)$ & $29(18.6)$ & $14(9.0)$ & $1(0.6)$ & \\
\hline Grade 3, 4 & $10(6.4)$ & $54(34.6)$ & $36(23.1)$ & $5(3.2)$ & \\
\hline Edmondson-Steiner grade (most) & & & & & .055 \\
\hline Grade 1, 2 & $14(9.0)$ & $57(36.5)$ & 30 (19.2) & $3(1.9)$ & \\
\hline Grade 3, 4 & $3(1.9)$ & $26(16.7)$ & $20(12.8)$ & $3(1.9)$ & \\
\hline Capsular invasion & & & & & .292 \\
\hline Absent & $17(10.9)$ & $65(41.7)$ & 40 (25.6) & $5(3.2)$ & \\
\hline Present & 0 & $18(11.5)$ & $10(6.4)$ & $1(0.6)$ & \\
\hline Early recurrence & & & & & .415 \\
\hline Absent & 38 (24.4) & 27 (17.3) & 18 (11.5) & $10(6.4)$ & \\
\hline Present & $26(16.7)$ & $13(8.3)$ & 13 (8.3) & $11(7.1)$ & \\
\hline
\end{tabular}

Values are presented as number (\%).

CRP, C-reactive protein; AFP, $\alpha$-fetoprotein; BCLC, Barcelona Clinic Liver Cancer.

in HBV-associated HCC cases (89.1\%); and (2) there is an inverse relationship between diffuse and strong CRP immunoreactivity and cancer-specific patient survival $(\mathrm{p}=.031)$. Notable variables significantly associated with CRP immunoreactivity also included tumor size, presence of satellite nodules, and serum CRP con- centration.

Hepatocellular carcinogenesis represents a classic model of viral etiology, and HCC is among the major causes of cancerrelated mortalities. ${ }^{13}$ The prevalence of hepatitis virus infection is relatively higher in East Asian countries. Chronic HBV infection 
Table 2. Clinical parameters and their relationship with CRP immunoreactivity

\begin{tabular}{|c|c|c|c|}
\hline Clinical parameters & $\begin{array}{c}\text { CRP grade } \\
0,1,2\end{array}$ & $\begin{array}{c}\text { CRP grade } \\
3\end{array}$ & $p$-value \\
\hline Sex & & & .719 \\
\hline Male & $110(70.5)$ & $4(2.6)$ & \\
\hline Female & $40(25.6)$ & $2(1.3)$ & \\
\hline Age (yr) & & & .586 \\
\hline$<60$ & $110(70.5)$ & $5(3.2)$ & \\
\hline$\geq 60$ & $40(25.6)$ & $1(0.6)$ & \\
\hline Tumor size (cm) & & & .137 \\
\hline$<5$ & $115(73.7)$ & $3(1.9)$ & \\
\hline$\geq 5$ & $35(22.4)$ & $3(1.9)$ & \\
\hline Serum AFP (ng/mL) & & & .585 \\
\hline$<400$ & $95(60.9)$ & $16(10.3)$ & \\
\hline$\geq 400$ & $40(25.6)$ & $5(3.2)$ & \\
\hline Serum CRP (mg/dL) & & & .000 \\
\hline$<1$ & $83(53.2)$ & $2(1.3)$ & \\
\hline$\geq 1$ & $8(5.1)$ & $3(1.9)$ & \\
\hline BCLC stage & & & .538 \\
\hline A & $141(90.4)$ & $6(3.8)$ & \\
\hline B & $9(5.8)$ & 0 & \\
\hline Fibrosis stage (Batts-Ludwig) & & & .929 \\
\hline Stage 1,2 & $23(14.7)$ & $1(0.6)$ & \\
\hline Stage 3,4 & $127(81.4)$ & $5(3.2)$ & \\
\hline Microvascular invasion & & & .890 \\
\hline Not identified & $104(66.7)$ & $4(2.6)$ & \\
\hline Present & $46(29.5)$ & $2(1.3)$ & \\
\hline Tumor number & & & .515 \\
\hline Less than 3 & $140(89.7)$ & $6(3.8)$ & \\
\hline 3 or more & $10(6.4)$ & 0 & \\
\hline Satellite nodule & & & .003 \\
\hline Absent & $143(91.7)$ & $4(2.6)$ & \\
\hline Present & $7(4.5)$ & $2(1.3)$ & \\
\hline Edmondson-Steiner grade (worst) & & & .395 \\
\hline Grade 1, 2 & $50(32.1)$ & $1(0.6)$ & \\
\hline Grade 3, 4 & $100(64.1)$ & $5(3.2)$ & \\
\hline Edmondson-Steiner grade (most) & & & .379 \\
\hline Grade 1, 2 & $101(64.7)$ & $3(1.9)$ & \\
\hline Grade 3, 4 & $49(31.4)$ & $3(1.9)$ & \\
\hline Capsular invasion & & & .570 \\
\hline Absent & $122(78.2)$ & $5(3.2)$ & \\
\hline Present & $28(17.9)$ & $1(0.6)$ & \\
\hline Early recurrence & & & .182 \\
\hline Absent & $91(58.3)$ & $2(1.3)$ & \\
\hline Present & $59(37.8)$ & $4(2.6)$ & \\
\hline
\end{tabular}

Values are presented as number (\%).

CRP, C-reactive protein; AFP, $\alpha$-fetoprotein; BCLC, Barcelona Clinic Liver cancer.

is more common than infection by hepatitis $\mathrm{C}$ virus (HCV) is, and more than half of HCCs are associated with HBV infection worldwide. ${ }^{14}$ Hence, we focused our analysis of the clinicopathologic significance of CRP immunoreactivity on non-neoplastic

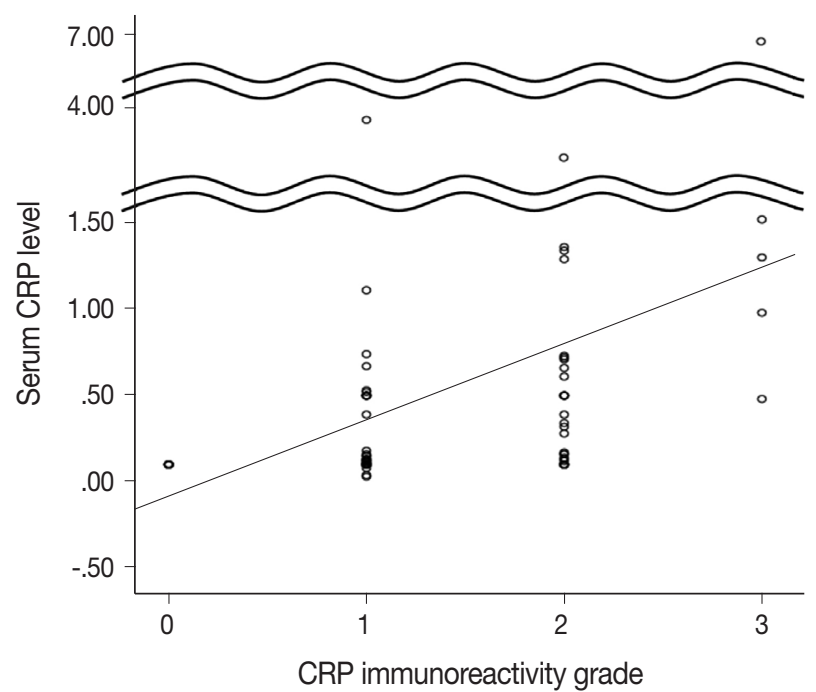

Fig. 2. Positive correlation between serum C-reactive protein (CRP) level and CRP immunoreactivity grades of non-neoplastic hepatocytes $(p<.001 ;$ rho $=0.513)$.

hepatocytes of HBV infection-associated HCCs. HBV infection increases the carcinogenic potential of hepatocytes, either by inducing chronic inflammation or direct integration into the host cell genome. ${ }^{11-15}$ The latter mechanism would explain HBV-associated HCCs in the absence of chronic hepatitis in the background liver. Chimeric integration of HBV genome into several host genes such as cyclin E1 and myeloid/lymphoid or mixed-lineage leukemia 4 has been documented by sequencing studies. The detection and sequencing of high-throughput viral integration done by Zhao et al..$^{16}$ revealed 4,225 HBV integration events in neoplastic and non-neoplastic liver tissues from 426 patients. Among HCCs with grade 3 hepatocytic CRP immunoreactivity in this study $(n=6)$, three cases were with mixed macronodular and micronodular cirrhosis, two cases were with chronic hepatitis, and one case was without significant background inflammation or cirrhosis.

We previously reported significant correlation between CRP immunoreactivity in HCC cells and patient survival. We looked at the relationship between HCC and corresponding non-neoplastic background liver in this study (data not shown) and found a significant correlation between the two, which indicated that both neoplastic and non-neoplastic hepatocytes are under a similar pro-inflammatory microenvironment in terms of CRP expression. ${ }^{12}$ Serum CRP has been consistently shown to be a key component of inflammation-based prognostication of HCC. ${ }^{17-19}$ The molecular mechanisms involved in the prognostic significance of CRP in HCC remain uncertain. However, a recent experimental investigation on CRP knockdown HepG2 cell proteome sug- 

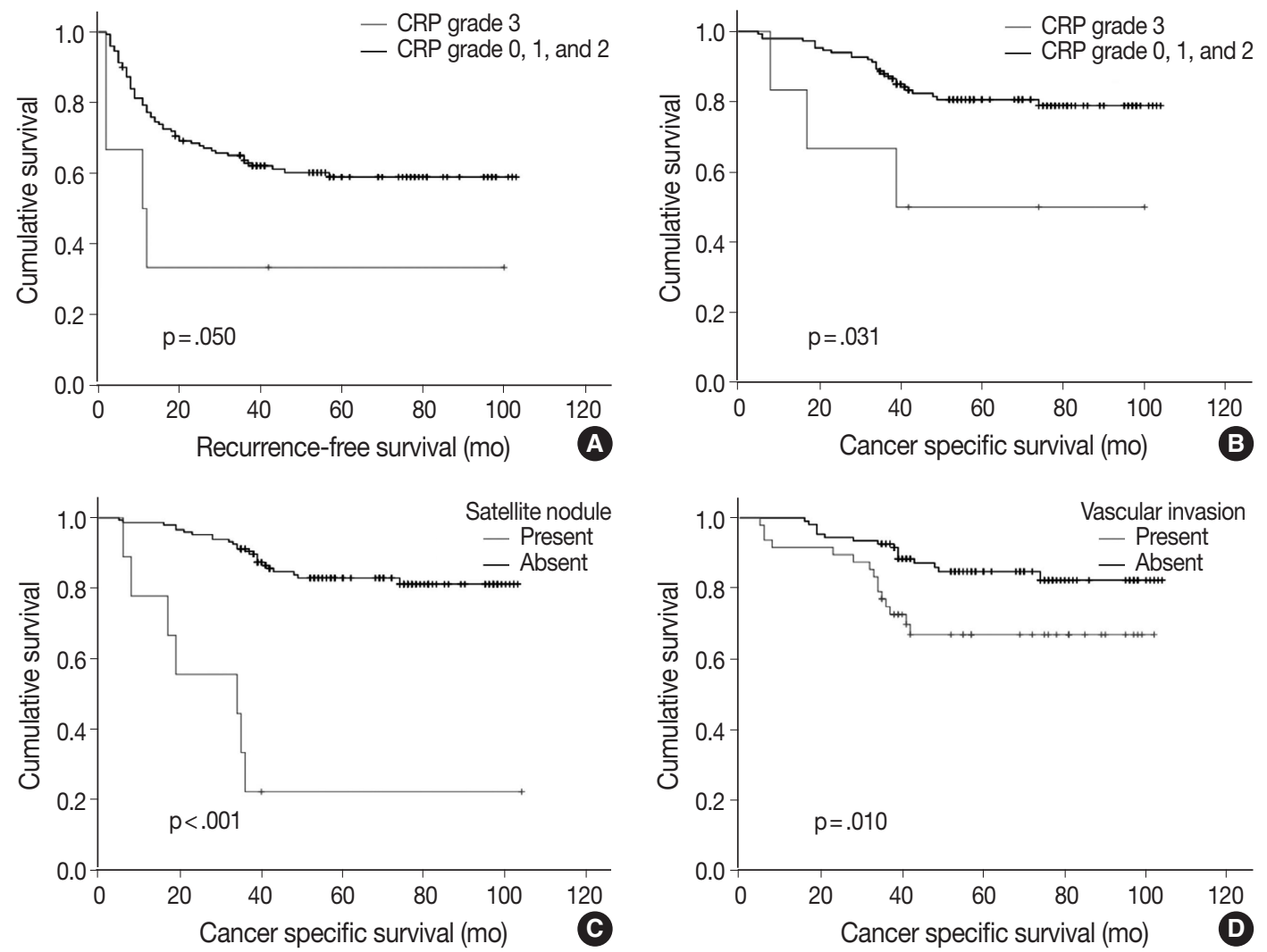

Fig. 3. Relationships between C-reactive protein (CRP) immunoreactivity of hepatocytes and patient outcomes. (A) There is a significant difference in cancer-specific survival between patients with CRP grade 3 immunoreactivity and those with CRP grade 0, 1, or 2 immunoreactivity $(p=.031)$. (B) There was a marginal difference in early recurrence of cancer between the 2 groups $(p=.050)$. (C, D) The presence or absence of satellite nodule (C) and vascular invasion (D) shows significant difference in cancer-specific survival period $(p<.001$ and $p=.001$, respectively).

Table 3. Factors affecting CRP immunoreactivity by multiple logistic regression analysis

\begin{tabular}{lccc}
\hline Clinical parameters & OR & $95 \% \mathrm{Cl}$ & $\mathrm{p}$-value \\
\hline Serum CRP & 12.229 & $1.573-95.087$ & .017 \\
Tumor size & & & .496 \\
Satellite nodule & & & .282 \\
\hline
\end{tabular}

CRP, C-reactive protein; OR, odds ratio; $\mathrm{Cl}$, confidence interval.

gested that CRP plays a role in promoting the migration, invasion, and metastasis of HCCs via activation of MEK/ERK and phosphoinositide 3-kinase/AKT signaling pathways. Notably, cathepsin $\mathrm{D}$ was among the proteins the expression of which was decreased in CRP knockdown cells. ${ }^{20}$ Other studies have also shown promotion of cell proliferation and antiapoptotic effects in different cell types such as renal tubular epithelial cells and myeloma cells. ${ }^{21,22}$

Although it is difficult to determine the relative contribution of HCC cells and non-neoplastic hepatocytes to serum CRP level, significant correlation between hepatocytic CRP immunoreactivity and blood CRP concentration supports the clinicopathologic significance of CRP as a surrogate prognostic marker of HBV-
Table 4. Cox regression analysis of parameters affecting cancerspecific survival in patients with HBV-associated hepatocellular carcinoma

\begin{tabular}{lcc}
\hline Clinical parameters & HR $(95 \% \mathrm{Cl})$ & p-value \\
\hline Satellite nodule & $7.457(3.004-18.514)$ & $<.001$ \\
Vascular invasion & & .077 \\
CRP immunoreactivity & & .063 \\
\hline
\end{tabular}

HBV, hepatitis B virus; HR, hazard ratio; $\mathrm{Cl}$, confidence interval; CRP, C-reactive protein.

associated HCC. Of note, Hu et al. ${ }^{23}$ proposed that HCC cells are not primarily responsive to serum hepatocyte growth factor, IL-6, and CRP based on the fact that the levels of these proteins go up after resection of HCCs, but this does not rule out the possibility of the significant contribution of HCC cells in affecting blood CRP level.

Regarding the association with tumor size, serum CRP level and tumor size were shown to be a marker of efficacy of transcatheter arterial chemoembolization (TACE) in HCCs. ${ }^{24}$ TACE reduced blood CRP level in HCC patients. ${ }^{25}$ Liu et al..$^{26}$ reported 
an association between preoperative serum CRP level and HCC tumor size and also found significantly decreased overall survival and recurrence-free survival in HCC patients with elevated serum CRP compared with those with normal serum CRP level. Another independent study by $\mathrm{Hu}$ et $a l^{23}$ demonstrated a relationship between tumor size and preoperative serum CRP level in HCC patients. A significant association with the presence of satellite nodule suggests the possibility of CRP expression and tumor growth characteristics. Kim et al. ${ }^{27}$ reported that CRP is an independent predictor of tumor recurrence in HCC cases with portal vein invasion.

The findings in this study indicate that CRP immunoreactivity in non-neoplastic hepatocytes is a novel prognostic biomarker of HBV-associated HCCs and is associated with certain tumor growth characteristics. The use of immunohistochemistry has merit in that the methodology is easily applicable to routine diagnostic pathology services. Further studies are needed to determine the significance of hepatocytic CRP immunoreactivity in cases with HCV-associated HCCs or nonvirally induced HCCs.

\section{Conflicts of Interest}

No potential conflict of interest relevant to this article was reported.

\section{Acknowledgments}

This study was supported by a grant (14-521) from the Asan Institute for Life Sciences, Seoul, Republic of Korea. The authors thank So Won Kim for her assistance in manuscript preparation and editing.

\section{REFERENCES}

1. Kushner I, Feldmann G. Control of the acute phase response. Demonstration of C-reactive protein synthesis and secretion by hepatocytes during acute inflammation in the rabbit. J Exp Med 1978; 148: 466-77.

2. Eklund CM. Proinflammatory cytokines in CRP baseline regulation. Adv Clin Chem 2009; 48: 111-36.

3. Ganter U, Arcone R, Toniatti C, Morrone G, Ciliberto G. Dual control of $C$-reactive protein gene expression by interleukin- 1 and interleukin-6. EMBO J 1989; 8: 3773-9.

4. Thompson PA, Khatami M, Baglole CJ, et al. Environmental immune disruptors, inflammation and cancer risk. Carcinogenesis 2015; 36 Suppl 1: S232-53.

5. Anuja K, Roy S, Ghosh C, Gupta P, Bhattacharjee S, Banerjee B.
Prolonged inflammatory microenvironment is crucial for pro-neoplastic growth and genome instability: a detailed review. Inflamm Res 2017; 66: 119-28.

6. Sicking I, Edlund K, Wesbuer E, et al. Prognostic influence of preoperative C-reactive protein in node-negative breast cancer patients. PLoS One 2014; 9: e111306.

7. Mori S, Kita J, Kato M, Shimoda M, Kubota K. Usefulness of a new inflammation-based scoring system for prognostication of patients with hepatocellular carcinoma after hepatectomy. Am J Surg 2015; 209: 187-93.

8. Kogo M, Sunaga T, Nakamura S, et al. Prognostic index for survival in patients with advanced non-small-cell lung cancer treated with third-generation agents. Chemotherapy 2017; 62: 239-45.

9. Liu Y, Chen S, Zheng C, et al. The prognostic value of the preoperative c-reactive protein/albumin ratio in ovarian cancer. BMC Cancer 2017; 17: 285.

10. Chen S, Yang X, Feng JF. A novel inflammation-based prognostic score for patients with esophageal squamous cell carcinoma: the creactive protein/prognostic nutritional index ratio. Oncotarget 2016; 7: 62123-32.

11. Takeda H, Takai A, Inuzuka T, Marusawa H. Genetic basis of hepatitis virus-associated hepatocellular carcinoma: linkage between infection, inflammation, and tumorigenesis. J Gastroenterol 2017; 52: 26-38.

12. Shin JH, Kim CJ, Jeon EJ, et al. Overexpression of C-reactive protein as a poor prognostic marker of resectable hepatocellular carcinomas. J Pathol Transl Med 2015; 49: 105-11.

13. El-Serag HB. Epidemiology of viral hepatitis and hepatocellular carcinoma. Gastroenterology 2012; 142: 1264-73.e1.

14. Levrero M, Zucman-Rossi J. Mechanisms of HBV-induced hepatocellular carcinoma. J Hepatol 2016; 64(1 Suppl): S84-S101.

15. Yang $X, W u$ L, Lin J, et al. Distinct hepatitis B virus integration patterns in hepatocellular carcinoma and adjacent normal liver tissue. Int J Cancer 2017; 140: 1324-30.

16. Zhao LH, Liu X, Yan HX, et al. Genomic and oncogenic preference of HBV integration in hepatocellular carcinoma. Nat Commun 2016; 7: 12992.

17. Kinoshita A, Onoda H, Imai N, Nishino H, Tajiri H. C-reactive protein as a prognostic marker in patients with hepatocellular carcinoma. Hepatogastroenterology 2015; 62: 966-70.

18. Zhao X, Luo J, Li B, Liu S, Li D. The association between preoperative serum $C$-reactive protein and hepatocellular carcinoma recurrence in patients with chronic hepatitis B virus (HBV) infection--a retrospective study. PLoS One 2015; 10: e0116909.

19. Nagaoka S, Yoshida T, Akiyoshi J, et al. Serum C-reactive protein levels predict survival in hepatocellular carcinoma. Liver Int 2007; 
27: 1091-7.

20. Shen S, Gong J, Yang Y, et al. Molecular mechanism of C-reaction protein in promoting migration and invasion of hepatocellular carcinoma cells in vitro. Int J Oncol 2017 Mar 13 [Epub]. https:/ /doi. org/10.3892/ijo.2017.3911.

21. Liu F, Chen HY, Huang XR, et al. C-reactive protein promotes diabetic kidney disease in a mouse model of type 1 diabetes. Diabetologia 2011; 54: 2713-23.

22. Yang J, Wezeman $M$, Zhang $X$, et al. Human C-reactive protein binds activating Fcgamma receptors and protects myeloma tumor cells from apoptosis. Cancer Cell 2007; 12: 252-65.

23. Hu RH, Lee PH, Yu SC. Secretion of acute-phase proteins before and after hepatocellular carcinoma resection. J Formos Med Assoc 1999; 98: 85-91.
24. Li Z, Xue TQ, Chen XY. Predictive values of serum VEGF and CRP levels combined with contrast enhanced MRI in hepatocellular carcinoma patients after TACE. Am J Cancer Res 2016; 6: 2375-85.

25. Jiang FQ, Lu W, Yang C, et al. Curative effect of transcatheter arterial chemoembolization combined with radiofrequency ablation in treating hepatic cell carcinoma and its effect on serum markers. Cancer Biomark 2017; 20: 17-22.

26. Liu YB, Ying J, Kuang SJ, et al. Elevated preoperative serum Hs-CRP level as a prognostic factor in patients who underwent resection for hepatocellular carcinoma. Medicine (Baltimore) 2015; 94: e2209.

27. Kim JM, Kwon CH, Joh JW, et al. C-reactive protein may be a prognostic factor in hepatocellular carcinoma with malignant portal vein invasion. World J Surg Oncol 2013; 11: 92. 